\title{
Chinese Ancient Locks: Shapes, Forms and Cultural Connotations
}

\author{
Peng Guoqing, Li Fuxing, Chen Peng, Cheng Yong \\ Xuzhou institute of technology, Xuzhou Construction Vehicles Appearance and Function Design \\ Research Center, Xuzhou 221008, China \\ E-mail:Saintlyboy@163.com
}

Keywords: Ancient Chinese locks; Shapes and forms; Decorative elements; Symbolic feature; Cultural connotation

Abstract: As important objects in Chinese folklore, ancient locks have a long history and close connection with the traditional culture. This article explores the various forms and symbolic meanings contained in Chinese ancient locks, aiming to articulate the cultural connotations shown in them. The different forms, techniques of expression, the exploration of human nature and pursuit of artistic purity embodied in ancient Chinese locks have great value for modern design, and function positively in traditional Chinese culture inheritance and development.

\section{Introduction}

Ci Yuan (the Chinese etymology dictionary first published in 1915) says, "Lock, is what peopled called 'jian' (key) in past and 'suo' (lock) now." Or, lock is a sealed device which can only be opened by a key. In ancient time, people wrapped valuable things in animal hide with a special tie by ropes, and opened it by a tool named "cuo". This was the prototype of ancient lock. In the late matriarchal society between 5000BC to 2000BC, some people accumulated treasure with the development of productivity. To protect their private properties, these people began to create an object functioning as a lock. Lunar Orders in the Book of Rites said in the first month of winter, people "strengthen the city walls, guard doors, build locks and keys carefully". So it is obvious that people in Western Zhou Dynasty (1046BC-771BC) used locks already[1].

\section{Shapes and Forms of Ancient Locks}

\subsection{Materials}

The Artificers' Record, a classic Chinese book on technical design said, "The sky has seasons, the earth has its air, the material has its beauty, and craftsman has his skill." It stresses the importance of material beauty. Wooden locks were found in Yangshao culture heritage in Neolithic Age (5000BC-3000BC); bronze locks were found in Shang and Zhou Dynasty (1600BC-250 BC), the most prosperous time for Chinese bronze wares; iron locks were made in Spring and Autumn Period (770BC-476BC) and the Warring States Time (475BC-221BC) when iron making techniques were made a breakthrough. In the Tang Dynasty and Song Dynasty, gold and silver were discovered; therefore, locks made of gold and silver were commonly used. Then in the Ming and Qing Dynasties, locks made by cupronickel were found. People in ancient time believed that gold and silver gave off invisible air, the so-call Jin chi and Yin chi which were thought capable of resisting 
ghosts' bad air. That's why the rich used locks made of gold, silver and ivory, the middle class used locks made of silver or animal horns, the medium or lower income households used locks made of copper, stone or wood[2].

\subsection{Shapes}

The shapes of ancient Chinese locks came from those of objects in people's lives and were the idealization of reality. This discovery in artistic expression was just the way artists used to interpret history and humanity. Classified by shape, ancient Chinese locks have circle ones, square ones, pillow-shaped ones, character-shaped ones, human image ones, animal image ones, plant image ones etc.

With the advance of foundry technique, ancient locks had various shapes and moulds. Foundry techniques were used in Shang and Zhou Dynasties. Moulds used roasted mud and pottery had been used in the early time. Later on, copper mould was used in minor quantity to cast many exquisite bronzes by casting technique. In the late Warring States Period, many iron moulds which could be used repeatedly were created and by using the same foundry technique, people could produce copper coins(Fig. 1).
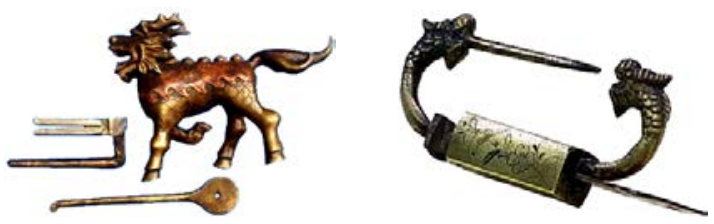

Fig.1 shapes and image

Among the many shapes and images of ancient Chinese locks, one kind was from the imagination and concretization of animals. Images like dragon, kylin, phoenix etc. are the products of people's totem worship. Ancient people wanted to give rich forms and deep cultural meanings to locks by using totems. In Fig. 1, for instance, the locks are the images of auspicious kylin and dragon. Kylin raised its head high and tail up with a commanding and ambitious air. The mouth of the kylin is the part through which the lock bar can enter and exit. Dragon was an auspicious animal to folk people, and was worshiped as the god of sea and water. Lock of Double Dragons Spitting Water has the image of two dragons face to face with the lock bar in the shape of water jet. Delicate flowers and birds were sculptured in the body of the lock with dragon shape, meaning that good weather for the crops and spectacular harvest of grain. Lock images like oxes, shrimps, magpie, Chinese lute, leaves, the legendary eight immortals etc. are the forms from people's lives. (Fig. 2) The form of Chinese lute used as the shape of locks has the implication of loved couple: "when the husband sings, his wife will follow, meaning they are devoted couple who grow old together." Locks with crane sculptured on it have the implication of having a long life, while the flying crane symbolizes career promotion. Locks in shape of shrimp always take the body of animal as its body with the tail coiled inward as lock bar, eyes made of copper wafers cornered by rings mimicking wide-open eyes of human being. The Eight Immortals were the Almighty Gods in folk beliefs, and had developed into one of the Chinese traditional mascots. Locks in Eight Immortals symbolize the meaning of good wishes and being safe. Yitong Divinatory Test says: "Magpie is a positive bird, responds before things happen." Therefore, magpie is considered as an auspicious bird which is capable of predicting the future guests and happen event. Locks in shape of magpie then was used to mean good luck. Locks in shape of a running ox with head moving forward, front legs drawing back, back legs stretching forcefully, tails sticking upward and the horns bend inward imply the meaning of fighting and working hard. Apart from their beauty in shapes, locks in shape of leaves had the meaning of "fallen leaves return to the roots", also implied the attachment feelings people had for their homeland[3]. 


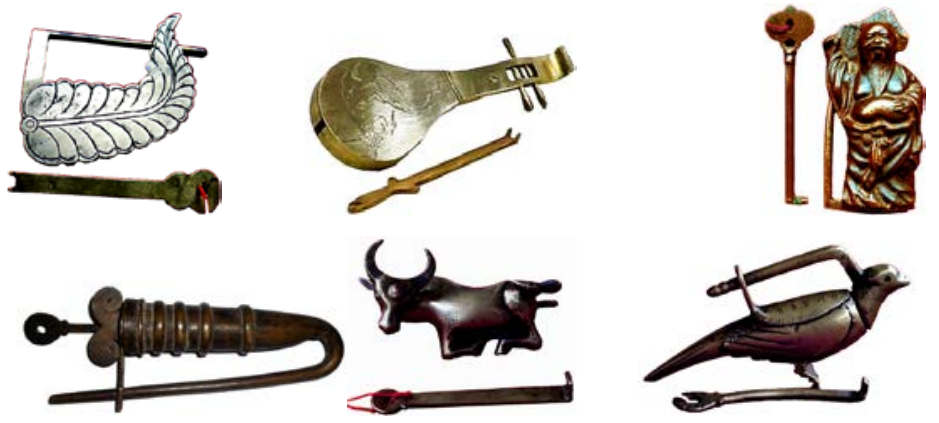

Fig. 2 Locks of Concretizations

Symmetry is another aesthetic principle embodied in ancient Chinese locks, which was acquired by people's observation of surroundings and themselves in their daily lives, representing a structural law in objects. (Fig. 3) The symmetric toad lock was a lock shaped in a toad with its front legs forming a loop, the keyhole located in the heart of the animal. On the back of the toad lock, two flying carps were sculptured as decoration. Toad and carp are two animals ancient Chinese believed may bring enormous wealth, and that's why they were regarded as fetish animals. Crab lock was a lock in the shape of a crab with its fore legs grabbing a twig, forming a complete loop, thus function as a lock. This gives the lock a dynamic feature, vivid and unadorned. The shell of the crab is called "jia", which has the same pronunciation as "san jia", the name of the examinee who got the highest score. So the implication of the lock is "being successful". Turtle is famous for its longevity, so its image was often used together with crane to mean having a long life.
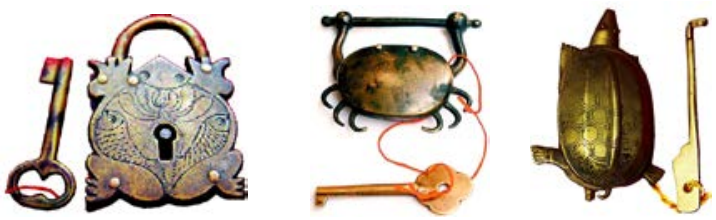

Fig.3 Locks in Symmetric Shapes

Ancient Chinese locks also contains the symbol of $R u$ Yi and Tai Chi, making them have deeper aesthetic meaning(Fig.4)Ancient people used cultural symbols into lock shape designs because of their decorative function. Moreover, they display the oriental characteristics related to the Chinese national emotions. For example, diagram of Tai Chi displays a formal beauty of transformation and unification, meaning good fortunes and harmony, which was very popular in folk people. $R u Y i$, invented in Wei and Jin Dynasties (220AD-589AD), used as an army demanding weapon for generals, was a symbol of power and influence. Later on, it became an object of good fortune and luck.
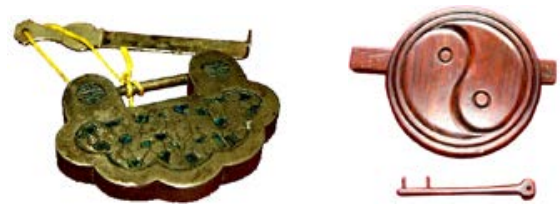

Fig.4 Locks of Cultural Symbols

\subsection{Decorations}

On the surface of ancient Chinese locks, carving, embossment, magnesium carving, molding etc. were applied for decorations, birds, animals, flowers, characters, landscapes, words and symbols were used to express certain meaning. For instance, locks for marriage usually used the locks with sculptured pictures like dragon and phoenix bringing prosperity, affectionate duck playing lotus, 
getting rich and old together, butterfly lovers to show the symbolic meaning of long and happy marriage. The development of decorative skill was another guarantee for the rich patterns on lock surface. Early in the Spring and Autumn Dynasties, people began to use mosaic in different colors on the surface of bronze wares. Then it developed into tiny grooves and artistic characters sculptured in by setting spun gold or silver. In the Warring Dynasty, metal dyeing and oxidation were also created which could be used to change the surface color of bronze wares into ink black to avoid rusting and use as decoration. Later on, paintings were made in the grooves of bronze wares' surface with gilding gold or silver[4].
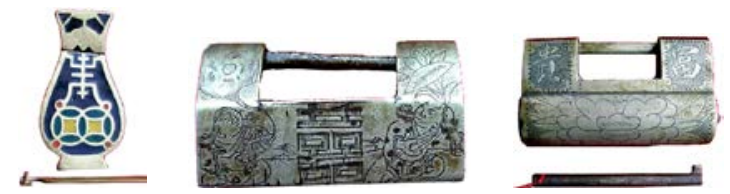

Fig.5 Ancient Locks’ Decorative patterns

Words are important symbols for thoughts expression and emotional communication. They can be used to express wishes, blessings etc. apart from for decorative patterns (Fig.5). Cupronickel locks with pattern of character “喜” in double and other plants carved on to present a very happy feeling. The ancient emperors and kings

Cloisonné calabash locks used as birthday gifts by ancient emperors and kings had pattern of “寿” carved on the upper part, two copper coins at the bottom were often to show the connotation that “寿”(health) is above wealth. As a symbol of auspicious flower, peony usually was used to present “wealth” (富). Locks with pattern of “富” omitted the “、” stroke on top on purpose was to express the meaning that May wealth grow without any limit, which is the essence of the golden means.

\section{Cultural Connotations in Ancient Locks}
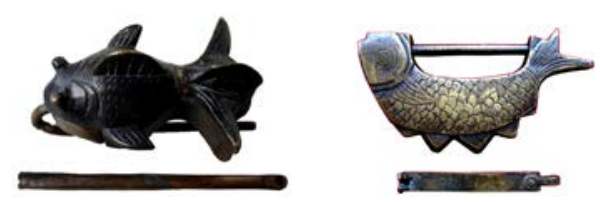

Fig. 6 Locks in Shapes of Fish
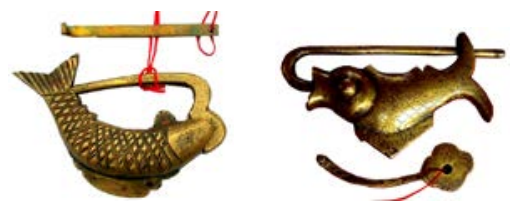

\subsection{Totem Worship}

In the matriarchal society, people had very short lives. Breeding was an important way to maintain human survival. People worship fish as a totem at that time because of the similarities between fish's shape and women's genital. Besides, fish has strong fertility and is seedy. So people in the ancient chose fish as their totem. In addition, Fish (“鱼”) has the same pronunciation as “余” (surplus )in Chinese, which means having more wealth than need. Till today, eating fish at the lunar New Year has become a tradition, and fish culture has been developed in Chinese traditions. With the influence of fish culture, fish locks were the most unique ones in shapes. (Fig.6) Dating back to the Spring and Autumn Dynasties, fish locks already emerged in record history book.

Biography of Gongyang in the Spring and Autumn Dynasties says: "the king ignores his duties, fish locks were neglected for defending." The king named Janwen in Liang Southern Dynasty once wrote in Night Thought in Autumn: The west door is gently shut with fish lock, the night bed is grief against painted screen.” Radom Essays in Writing recorded: "In the old king palace in Song Dynasty, fish locks and fish keys made in ancient time were used.” Ding Yonghui (a knowledgeable man) in Song Dynasty said in his Record of Zhitian, the second volumn: "People use fish locks for its 
forever open eyes, hoping for their properties would be protected all night long." A person named Wei Song in Qing Dynasty wrote in Yi Shi Ji Shi (an Encyclopedia and dictionary), " Locks in Zhou Dynasty were made in the shapes of fish, because fish keep eyes open all the time." Because of this, the cultural connotation had been developed about fish locks that properties with would be protected by keeping eyes open all the time just as the fish [5].

\subsection{Symbols of Blessings or Amulets}
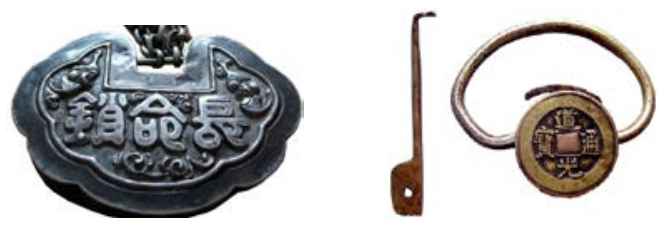

Fig.7 Longevity Locks

As a symbolic object in folklore, Chinese ancient locks had many cultural connotations, reflecting people's psychology, aesthetic consciousness, customs etc.. They were placed in a prominent position and became the symbols of fortune and amulets. Long life locks, fish locks, locks with double “喜” patterns in etc. reflect people's good wishes and thoughts for life, descendants, marriage and career. For instance, locks on dowry of a bride in a marriage ceremony were called the twelve zodiac lock, on coffins the blessed long life locks, all showing the good wishes $^{[6]}$. The amplification of lock's function made people believe that something intangible might be locked too. Children with long-life locks on their necks were hoped that health were locked in and were diseases locked out so they would grow up safely (Fig.7). Giving a long-life lock as a birth gift to a newly-born baby was very popular in folks. If a family had a newly born baby, his or her families would borrow money in coins from neighbours to forge a long-life lock, hoping that the baby would be healthy with the good wishes of these people. Those who had family names as 陈、孙、刘、胡 were especially popular in this money borrowing family list, because the sound of their family names are quite the same as the pronunciations of “存” (survival)、“生” (aliveness)、 “留” (growing)and “护” (protection). All these had the good and positive meanings. Yan Sheng, a Chinese old witchcraft, was thought being capable of cursing and defeating human beings or objects. People in Han Dynasty used Yan Sheng money to replace long-life locks, thus derived the coming of copper coins or amulets on which kinds of auspicious words like “千秋万岁” (thousands of years)、“去殊除凶” (eliminating sufferings and evils) were carved on heads, patterns of double fishes, dragon and phoenix, turtle and snakes etc on tails. Customs were held that Yan Sheng coins hung on children's neck also had the similar functions.

\subsection{Symbols of Power}

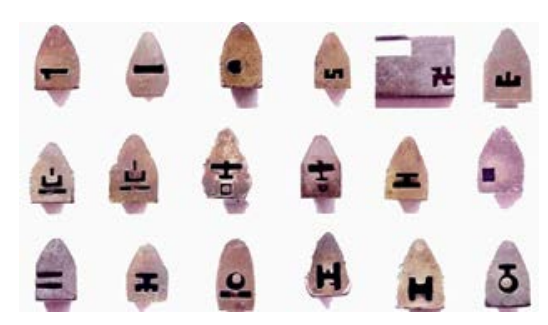

Fig.8 Shapes of Keyholes

Keyholes of Chinese ancient locks reflect the strict hierarchy system in the federal society, showing the social classes of the land owners. The keyholes were often in the shapes of Chinese characters like “一”、“上”、“工”、“古”、“尚、”吉”、“喜”、“寿”etc.(Fig.8)The massive common 
people were permitted to use the keyholes in shape of “一”(one)only, people of “士大夫”( those in the literati and officialdom) used keyholes in shapes of “士”, high officials and noble lords in “吉”,people getting married in “喜”,senior family members in their birthday in “寿” wishing being healthy and living long[6].

\section{Conclusion}

As important carriers of culture and customs, ancient Chinese locks reflect the cultural connotations via their materials, shapes and decorations, show the aesthetic value and value for culture research, and fully display the ancient Chinese people's intelligence and creativity. By studying the ways ancient locks displaying cultural connotation, we hope to provide some thoughts and concepts for design in today and make it spread vigorously as well as inheriting the cultural traditions.

\section{References}

[1] Hongyan Guan,Fengyu Yang,Qilei Wang.Study on evaluation index system of rubber materials for sealing, J. Materials and Design.32(2011) 2404-2412.

[2] Poirson Emilie,Petiot Jean- Franois,Richard Florent.Amethod for perceptual evaluation of products by naive subjects: Application to car engine sounds, J.International Journal of industrial ergonomics.40(2010) 504-516.

[3] Lin Chyunchau,Luh dingbang.A vision- oriented approach for innovative product design [J]. Advanced Engineering Informatics, 23(2009) 191-200.

[4] TENG Jia-hua. The Design of Product Image Based on Brand Strategy[J].Journal of Shandong University of Technology,2007(1):99-101 .

[5] HU Jie. Multimedia Creative Art[J].Beijing Journal of University of the Arts,2008,19(4):78-81 .

[6] LI Shi-guo,GU Zhen-yu. Interaction Design[M].Beijing:China Water Power Press,2012 . 